\title{
UNA ESPECIE NUEVA DE PLINIA L. (MYRTACEAE) DEL CARIBE SUR DE COSTA RICA
}

\author{
Jorge GOMEZ-LAurito ${ }^{1,2}$ y OSCAR VALVERdE ${ }^{1}$ \\ ${ }^{1}$ Escuela de Biología, Universidad de Costa Rica, Ciudad Universitaria 2060, San José, Costa Rica \\ ${ }^{2}$ Investigador Asociado, Dept. of Botany, Field Museum of Natural History, Chicago, U. S. A.
}

\begin{abstract}
A new species of Plinia L. (Myrtaceae) with conspicuosly cuspidate leaves, small flowers and oblate, asymmetric, smooth, and strongly compressed fruits is described from the southern Caribbean region of Costa Rica.
\end{abstract}

Resumen. Una nueva especie de Plinia L. (Myrtaceae) con hojas conspicuamente cuspidadas, flores pequeñas y frutos oblados, asimétricos, lisos y fuertemente comprimidos, se describe de la región Caribe sur de Costa Rica.

KEY WORDS:

Plinia L. (Myrtaceae) es un género neotropical con 10-30 especies, la mayoría de ellas sudamericanas (Gentry 1993, Mabberly 1997) y se caracteriza por tener flores sésiles o subsésiles, pubescentes, con 2 óvulos en cada lóculo, subtendidas por brácteas y formando glomérulos por lo general caulifloros y semillas con cotiledones libres y plano convexos (Gentry 1993). McVaugh (1963) describió por primera vez una especie de Costa Rica con base en el material recolectado en 1931 por Alberto M. Brenes en la región de Cataratas de San Ramón, provincia de Alajuela. Se trata de $P$. salticola McVaugh, que se encuentra también en el área de Monteverde y en los Cerros de Puriscal y Turrubares, entre 850 y 1600 m de elevación. Más recientemente, otras dos especies de este género se han sumado a la flora costarricense: $P$. povedae $\mathrm{P}$. E. Sánchez, distribuida en la Península de Osa, en la región de Tinamaste de Pérez Zeledón y en Fila Matama de la estribación Caribe de la Cordillera de Talamanca, entre 200 y 650 m de elevación, y $P$. puriscalensis $\mathrm{P}$. E. Sánchez \& Q. Jiménez de la Zona Protectora La Cangreja en Puriscal, entre 600 y $700 \mathrm{~m}$ de elevación. Como resultado de la exploración botánica realizada por uno de los autores en las tierras bajas del Caribe sur, otra especie de Plinia ha sido descubierta y se describe a continuación.
Plinia cuspidata Gómez-Laur. \& Valverde, sp. nova FIG. 1.

TIPO: Costa RicA. Limón: Talamanca. Bratsi. Buena Vista. Finca ACODEFO. Bosque intervenido en lomas de Fila Carbón. $300 \mathrm{~m}$ de elev. 9॰39'30" N, 8352'30" W. 25 nov. 2000. $O$. Valverde \& S. Mora 1339 (Holotipo USJ).

Species insignis ramulis distalis complanatis, sericeis, folia conspicue cuspidata, flores parvulis, fructus oblatus valde complanatus, asymmetricus, laevis a speciebus nobis bene distincta.

Árbol 8-20 m de altura y $16-30 \mathrm{~cm}$ de DAP, caulifloro, el tronco recto y cilíndrico con la corteza externa lisa, exfoliante, con cicatrices crateriformes muy marcadas, la interna rojo oscuro con líneas amarillas, el duramen amarillo claro. Ramitas ca. 2 $\mathrm{mm}$ de diámetro, seríceas, teretes pero aplanadas en los extremos donde se insertan las hojas. Hojas con pecíolos 8-10 mm de largo y 1,5-2 $\mathrm{mm}$ de diámetro, teretes, seríceos; láminas foliares elípticas, 12$16 \mathrm{~cm}$ de largo y 3-6 cm de ancho, conspicuamente pelúcido-punteadas, con 17-19 pares de venas principales y una vena submarginal a $2-5 \mathrm{~mm}$ del margen, glabras e inmersas por el haz, seríceas y levantadas por el envés, venas terciarias reticuladas, la base cuneada, el ápice conspicuamente cuspidado, el margen entero, ligeramente involuto. 


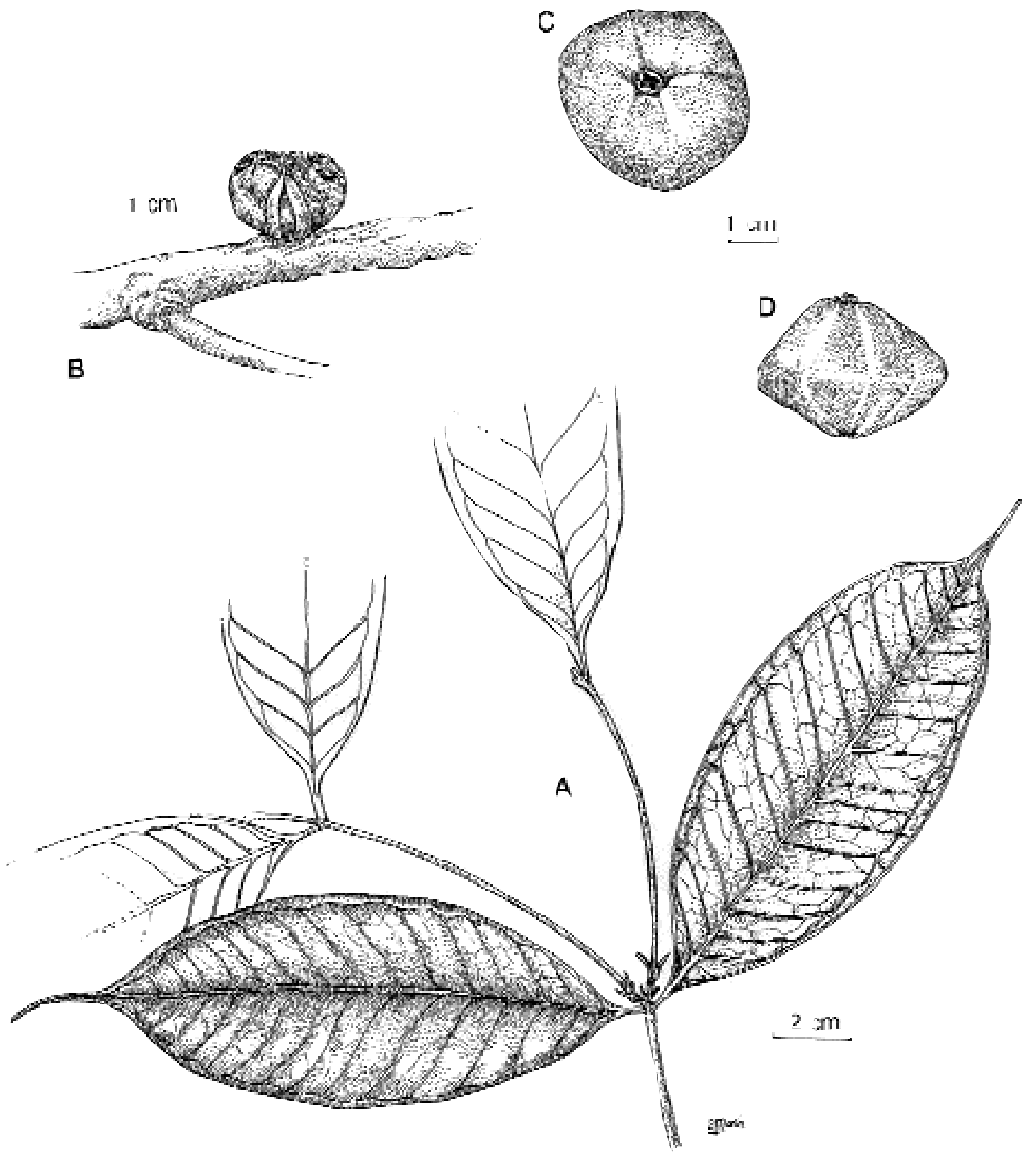

Figura 1. Plinia cuspidata Gómez-Laurito \& Valverde. A - Hábito. B - Inflorescencia. C - Fruto, vista apical. D Fruto, vista lateral. TESTIGO: O. Valverde \& S. Mora 1370.

Inflorescencias en tronco, ramas y aún ramitas; las flores en fascículos de 4, sésiles, a veces madurando primero 2 y luego otras 2 , cada fascículo con 8 brácteas de color verde en 2 verticilos, 4 brácteas grandes de 2-3,5 $\mathrm{mm}$ de largo, lanceoladas, pilosas y 4 brácteas más pequeñas, 1-1,5 mm de largo, lan- ceoladas y glabras; 4 bracteolas de 1-1,3 mm de largo, lanceoladas y glabras. Cáliz con 4 lóbulos, los lóbulos lanceolados, 3-4 mm de largo y 2,5 mm de ancho, estrigosos, casi tan largos como los pétalos. Pétalos blancos, densamente estrigosos, reflexos y permanentes luego de la antesis, glabros 
y glandular punteados internamente. Botones florales $9-10 \mathrm{~mm}$ de largo, turbinados, densamente cubiertos por una pubescencia estrigosa castaña. Estambres ca. 130, insertos en la parte superior del hipanto, completamente incurvados, anteras ca. 0,5 $\mathrm{mm}$ de largo, amarillo claro, bitecas, dehiscentes longitudinalmente. Estilo 3-4 mm de largo, inserto, el estigma capitado, pardo rojizo, apenas exserto. Hipanto glabro, acopado, glandular-punteado. Ovario bilocular con 2 óvulos en cada lóculo; los óvulos reniformes, ca. $1 \mathrm{~mm}$ de largo. Frutos sésiles, amarillos cuando maduros, oblados, fuertemente comprimidos, asimétricos, lisos, 3,5-4 cm de diámetro y $3 \mathrm{~cm}$ de grosor, coronados por los lóbulos del cáliz.

Plinia cuspidata se distingue por sus ramitas seríceas y aplanadas distalmente, sus hojas conspicuamente cuspidadas (de ahí su epíteto), sus flores muy pequeñas y sus frutos oblados, fuertemente comprimidos, asimétricos y lisos.

En la localidad típica la especie es más bien escasa, presentándose frecuentemente como arbolito del sotobosque y en menor grado como árbol del subdosel. En el bosque es fácil de reconocer por el color y textura de la corteza. En arbolitos jóvenes la corteza es similar a la de guayabo (Psidium guaja$v a \mathrm{~L}$.), por lo que son muy conspicuos. La regeneración es escasa bajo los árboles observados y lo usual es encontrar individuos aislados. Por lo general se le encuentra en terrenos ondulados, con buena escorrentía, asociada a especies como Iriartea deltoidea (Arecaceae), Pentaclethra macroloba (Mimo-saceae), Hura crepitans (Euphorbiaceae), Brosimum lactescens (Moraceae),
Virola multiflora (Myristicaceae), Alseis blackiana (Rubiaceae) y Siparuna guianensis (Siparunaceae), entre otras (Valverde 1998). En una zona Tropical, Tropical, húmeda sin meses secos, de acuerdo al mapa de unidades bióticas de Costa Rica (Herrera \& Gómez 1993).

PARATipos: Costa Rica. Limón: localidad típica, abril de 2001 (flores), O. Valverde \& S. Mora 1370 (CR, USJ, F).

Agradecimientos. Al personal del Corredor Biológico Talamanca Caribe, en especial a Cristián Rodríguez, Magaly Zúñiga, José L. Zúñiga y Sebastián Hernández, por su compañía y ayuda en las giras de recolecta. A Guillermo Mora por permitirnos trabajar en su finca y a Carmen Marín por la excelente ilustración.

\section{LITERATURA CITADA}

Gentry, A. H. 1993. A field guide to the families and genera of woody plants of Northwest South America. Conservation International. p. 652.

Herrera, W. \& Gómez, L. D. 1993. Mapa de unidades bióticas de Costa Rica. Escala 1:685.000. Instituto Geográfico de Costa Rica.

Mabberley, D. J. 1997. The plant-book. 2. ed. Cambridge University Press. p. 569.

McVaugh, R. 1963. A new species of Plinia L. from Costa Rica. Fieldiana, Bot. 29(8): 505, f. 13. 1963.

Valverde, O. 1998. Estructura forestal y patrones florísticos de dos bosques tropicales húmedos de la Cordillera de Talamanca, Costa Rica. Brenesia 49-50: 39-60. 